ISSN: 2639-0574

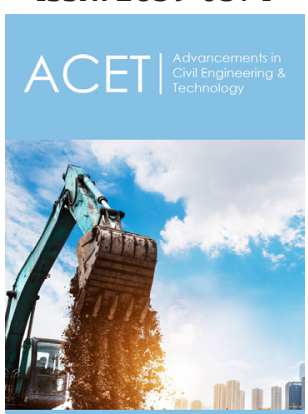

${ }^{* 1}$ Corresponding author: Guoqing $\mathrm{He}$, College of Civil Engineering and Architecture, Zhejiang University, China

Submission: 海June 10, 2019

Published: 梅June 13, 2019

Volume 3 - Issue 3

How to cite this article: Guoqing HE, Ventilation and Humidity Control in Underground Utility Tunnel: an UnderStudied Topic. Adv Civil Eng Tech. 3(3). ACET.000562.2019.

DOI: 10.31031/ACET.2019.03.000562

Copyright@ Guoqing He, This article is distributed under the terms of the Creative Commons Attribution 4.0 International License, which permits unrestricted use and redistribution provided that the original author and source are credited.

\section{Ventilation and Humidity Control in Underground Utility Tunnel: an Under-Studied Topic}

Guoqing $\mathrm{HE}^{1 *}$, Zhao $\mathrm{W}^{1}$ and Wang $\mathrm{L}^{2}$

${ }^{1}$ College of Civil Engineering and Architecture, Zhejiang University, China

${ }^{2}$ CCDI (Suzhou) Exploration \& Design Consultant CO Ltd, China

\section{Background}

Underground utility tunnel refers to a passage built underground to accommodate two or more types of urban engineering pipelines, including water supply pipes, sewer pipes, steam, gas, electricity, fiber optics, television cables, telephone cables, etc. It allows not only comprehensive utilization and resource sharing of underground space but also an easy and safe access to these service infrastructures for regular inspections and maintenance that would otherwise require recurring street works in the case of direct burial trenches, impacting on traffic, business, and environment. The initial investment is high but can be compensated by later benefits in maintenance.

Modern municipal utility tunnels can be dated back to 1850's when Paris built its first man-accessible tunnel that hosted water supply, sewage, and compressed air pipelines [1]. Since then many cities have embraced the ideas of utility tunnels to improve the quality of municipal services and city resilience. For example, in Japan, utility tunnels are considered effective in reducing the catastrophic effects of earthquakes. Though China built its first utility tunnel in 1959, not until recent years has the country seen fast and rapid development. Having long been troubled by frequent flooding and the repeat street excavation for utility maintenance, the Chinese government launched a large promotion plan for the construction of utility tunnel and released its first technical code in 2015 [2]. From 2015 to 2016, the government financially supported 25 pilot cities for the construction of utility tunnels with a target of $2000 \mathrm{~km}$ [3]. Figure 1 shows the cross-section of one standard tunnel section in Suzhou, one of the pilot cities. A typical standard section is $200 \mathrm{~m}$ long while it could be 400 meters for some cabins.

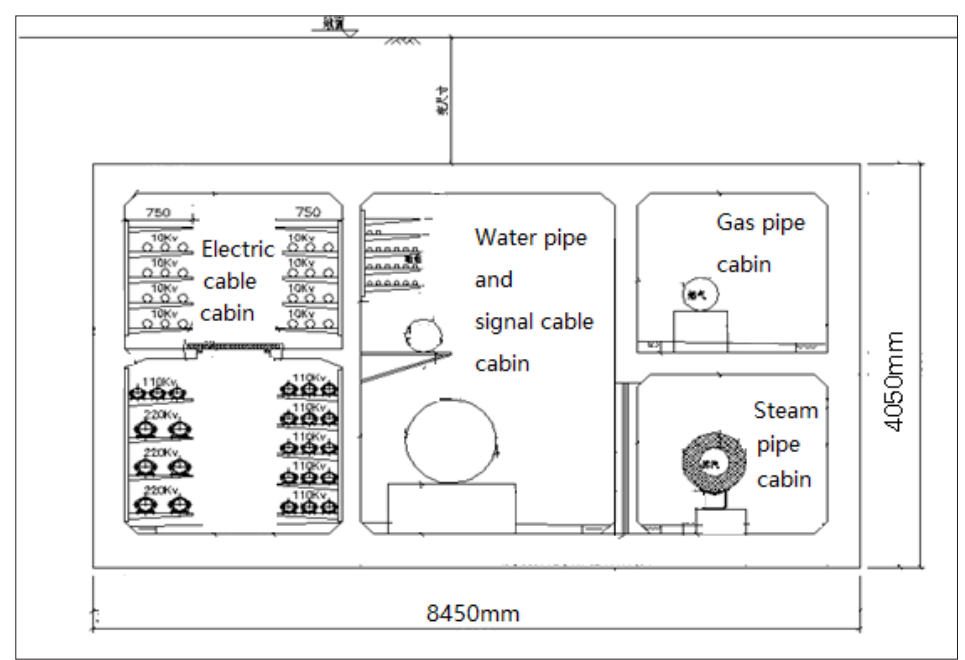

Figure 1: A typical cross-section of underground utility tunnel in Suzhou, China. 
The typical underground utility tunnel is equipped with ventilation, illumination, monitoring, fire suppression, and other security systems to keep the cabin environment in an operable and safe condition. Due to the underground nature, ventilation and illumination could be energy consuming. However, the optimization of these systems, the air quality, and the energy efficiency are among the under-studied areas.

\section{Ventilation}

There are risks to the air quality of the underground spaces due to the microorganism growth, the depletion of oxygen, the emission of harmful gases, and heat released from some utility lines. An effective ventilation system is important to ensure a safe and healthy environment condition in the tunnel. In China, the code requires that the cabin hosting gas lines is ventilated at least 6 air change rates (air is refreshed 6 times every hour) while the rest types of cabins are ventilated at least 2 air change rates [2]. In practice, however, ventilation systems for cabins with heat sources, such as cabins for steam pipelines and electricity cable lines, are designed with larger ventilation rates so that the cabin air temperature will not exceed a safe level for workers. Ventilation can be achieved by either natural ventilation or mechanical ventilation. Mechanical ventilation is achieved by either of the two means: mechanical exhaust with natural intake and mechanical intake with mechanical exhaust.
The proper sizing of the fans is important to ensure the environment quality and energy efficiency. Because of the size of the cabins, the ventilation rate is large and the energy consumption is high. In practice, cabins in use are only ventilated when maintenance work are needed for energy saving purpose. In addition, there is not much study on the ventilation effectiveness and air quality in the cabins.

\section{Moisture problem}

In some regions, the underground utility tunnel features high relative humidity most time of the year. The high relative humidity in the tunnel is due to the presence of various water sources: trapped water in the enclosure cement structure, transport of moisture from surrounding soil through enclosure structure, seepage water through enclosure structure, and other water residual from maintenance work. However, the ventilated air can be the dominant moisture source if the outside air is more humid than the cabin air. In such conditions, ventilation can lead to sever condensation inside the tunnel. For example, in regions along the lower part of the Yangtze River basin, the outdoor air is wetter than the saturated cabin air during the summer as shown in Figure 2, which compares the measured humidity in a cabin without heat sources with the ambient air humidity of a typical meteorological year in Suzhou, China. In such condition, outdoor air condensates along the cabin wall after entering into the cabin as a result of ventilation.

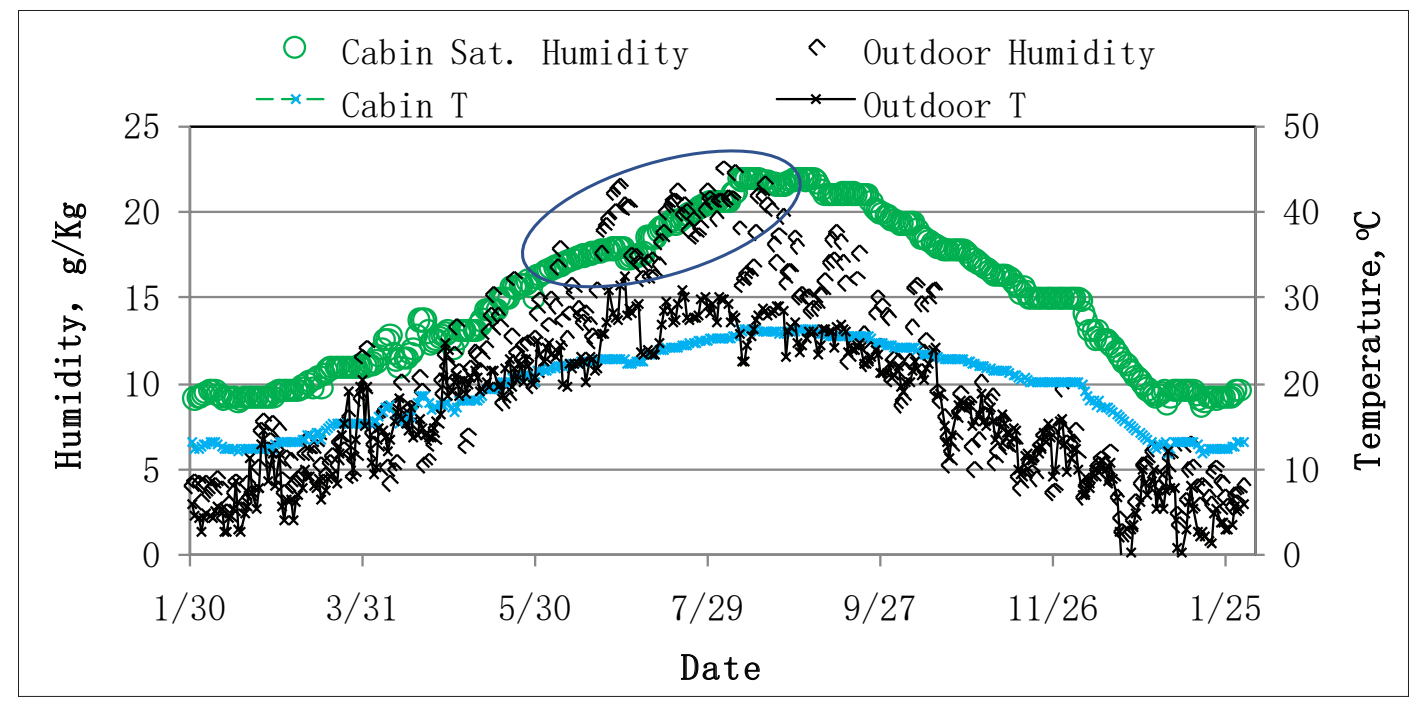

Figure 2: Comparison between the measured temperature and humidity in the cabin without heat sources and the ambient temperature and humidity in a typical meteorological year in Suzhou, China.

The humid condition and condensation in the cabin cause problems to the operation of the utility tunnel, including shortened lifetime of sensors, corrosion and break down of mechanical actuators, and the deterioration of air quality. Therefore, not only economic losses are profound but also the working condition is at risk for the maintenance workers. Unfortunately, the humidity problem is hardly addressed in the current design and construction practice of the utility tunnel. In practice, in order to mitigate condensation in the tunnel, the ventilation system is often kept closed during the rainy days in summer, thus leading to insufficient ventilation in cabins. Insufficient ventilation can cause the deterioration of air quality, putting the workers' health at risk.

\section{Humidification method}

From the above analysis, the environmental quality and the moisture problem call for the need for a dehumidification system for the ventilation system. The proper design of the dehumidification system involves the control strategy of the ventilation system, 
the heat transfer between the tunnels and the soil, and the refrigeration and dehumidification system. In current practice, the fan is often oversized for cabins with internal heat sources without the consideration of the cooling effect of the dehumidification. At present, there are three major dehumidification methods in the market: condensation dehumidification, solid adsorption dehumidification and solution absorption dehumidification.

Condensation dehumidification is a mature technology with less initial cost. It provides cooling and dehumidification at the same time. But it is energy disadvantageous when cooling is not needed, or very dry air is needed. The solid adsorbent dehumidification could be energy efficient if the generation of adsorbent uses renewable energy. Otherwise it is an expensive and energy inefficient technology. But it can achieve very dry air. Dehumidification using solution absorption has similar effect as solid adsorbent dehumidification and is advantageous when air purification is needed. Because the solution is mostly saline, corrosion is a challenge.

\section{Summary}

The urban underground utility tunnel is increasingly recognized for its benefits in municipal service and city resilience. The Chinese government has recently launched campaigns to promote a largescale construction of utility tunnels nationwide through pilot cities and financial subsidies. However, there is not enough attention paid to the environmental quality of the cabins in the tunnel. Much study is needed to optimize the ventilation and humidification strategies for energy efficiency and environmental quality.

\section{References}

1. Wang T, Tan L, Xie S, Ma B (2018) Development and applications of common utility tunnels in China. Tunnelling and Underground Space Technology 76: 92-106.

2. http://www.mohurd.gov.cn/wjfb/201508/t20150828_224135.html

3. http://www.gov.cn/guowuyuan/2016-03/05/content_5049372.htm

For possible submissions Click below: 